\title{
A Study on Chemical Characterization and Proximate Composition of Flathead Mullet Fish (Mugil cephalus) of Estuarine Region of the Bay of Bengal
}

\author{
M. Rowshan-Ali ${ }^{1}$, M. A. H. Roni ${ }^{1, *}$, M. A. Haque ${ }^{2}$, M. H. Uddin ${ }^{2}$ \\ ${ }^{1}$ Applied Chemistry Research Laboratory, Department of Chemistry, University of Chittagong, \\ Chittagong - 4331, Bangladesh \\ ${ }^{2}$ Department of Applied \& Environmental Chemistry, University of Chittagong, \\ Chittagong - 4331, Bangladesh \\ *E-mail address: hasan.chemist@yahoo.com
}

\begin{abstract}
The Flathead mullet (Mugil cephalus) is a mullet of the genus Mugil in the family Mugilidae, found in coastal tropical, subtropical and estuarine water worldwide. Lipid was extracted from the muscle of Flathead mullet (Mugil cephalus) by solvent extraction method and characterized with respect to various chemical e.g. saponification value, saponification equivalent value, acid value, iodine value, peroxide value, ester value, thicyanogen value, unsaponifiable matter, Henher value, Polenske value, Reichert-Meissl value etc properties and compared with those of different oils. Palmitic acid, Stearic acid and Myristic acid were observed at fatty acid composition of the sample by chromatographic examination. Percentages of protein and mineral $(\mathrm{N}, \mathrm{P}, \mathrm{K}, \mathrm{Ca})$ in the muscle of Flathead mullet were studied by modified Kjeldahl method.
\end{abstract}

Keywords: Coastal-Tropical; Polyunsaturated fatty acid (PUFA); Proximate composition

\section{INTRODUCTION}

The Striped Mullet normally occupies fresh, brackish and marine habitats in depths ranging between 0-120 meters (0-394 ft) and with temperatures between 8-24 ${ }^{\circ} \mathrm{C}$ (Minckley, 1973). Flathead mullet (Mugil cephalus) is a moderate sized fish found plenty in the coastal belts of the country, Bangladesh. But local people are not aware about the importance of this fish and sufficient data of the food value and pharmaceutical aspects are not available also. Many marine fishes are rich in lipids (oil) which provides mainly 16:0 and 18: 1 fatty acids including pharmaceutically important omega-3 pollyunsaturated fatty acids $(\Omega-3$, PUFA) (Quazi et al., 1994)). Important influence of the fish oil on the serum lipid and lipoprotein profiles in human subjects was found (Siddique et al.,1994). Its effect on the lipid profile in normotensive subjects (Siddique et al., 1995a), hypertansive subjects (Siddique et al., 1995b) and patients with nephritic syndrome (Chowdhury et al., 2001) have also been mentioned. Now a day's researchers are giving more concentration to the chemical analysis \& proximate 
composition of various fishes (Rajagopalan et al., 2013; Sankar et al., 2013). However, results of such types of studies on Flathead mullet (Mugil cephalus) are very unknown or less reported but this fish is found plenty in our coastal belts. The flathead mullet is an important food fish for many around the world, and can be both fished and farmed. Though the Flathead mullet (Mugil cephalus) is found in estuarine region so it may have slightly different property then other marine fish or fresh water fish. Mullet does not keep well after it is caught. If kept on ice it may remain edible for approximately 72 hours, after which it becomes nearly inedible. The sooner it can be eaten after being caught, the better. So to know in details of its chemical characteristics this sample was studied.

Present study is about the chemical characterization of the solvent-extracted oil from the muscle of Flathead mullet (Mugil cephalus) local coastal belts and comparing the results with the data available in literature about chemical aspects of muscle lipid of Flathead mullet Percentages of protein and mineral $(\mathrm{N}, \mathrm{P}, \mathrm{K}, \mathrm{Ca})$ in the muscle of Flathead mullet were studied.

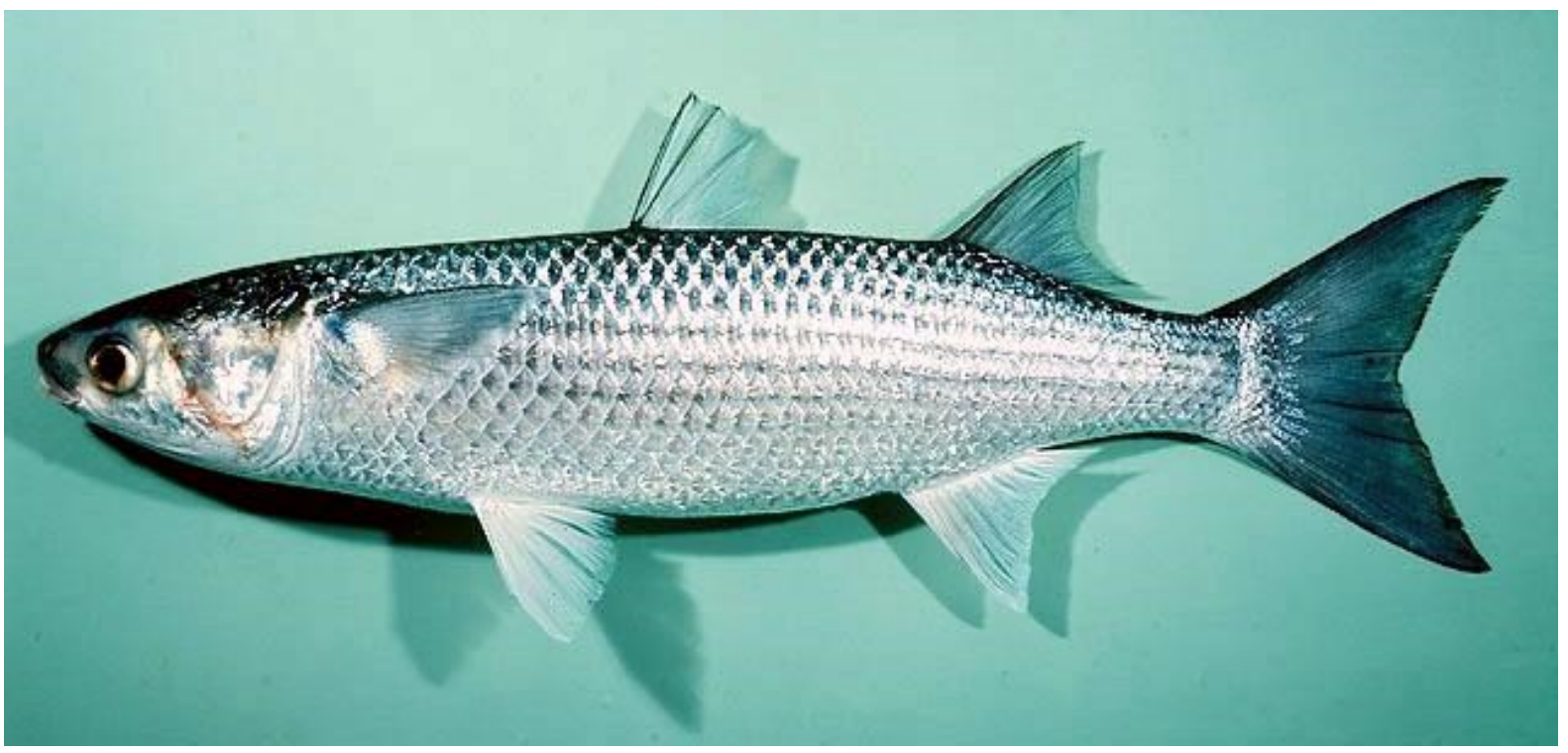

Photo 1. Mugil cephalus.

\section{EXPERIMENTAL}

Flathead mullet (Mugil cephalus) was collected from the local fish supplier and identified in the Institute of Marine Science \& Fisheries, University of Chittagong. The muscle of the fish was treated by solvent extracted method to extract the lipid. The extract was then dried free of solvent by rotary evaporation and finally by blowing a slow stream of nitrogen gas. Saponification value, saponication equivalent value, acid value and percentage of free fatty acid (as oleic acid), iodine value acetyl value (Griffin, 1972), peroxide value (Morris, 1965), Thiocyanogen value, Richert Meissl value and Polenske value (Ranganna, 1991), Henher value, Elaiden test result (Das, 1989) and quantity of un saponifiable matter (Williams, 1966) of the muscle lipid of Flathead mullet were determined by standard methods. Thin layer chromatographic (TLC) investigation of the fatty acids present in the fish oil system was done in various solvent systems (Loury, 1966). Cholesterol and proximate composition of the sample were studied with the standard methods. 


\section{RESULTS AND DISCUSSION}

Table 1. Chemical constants of the muscle lipid of Flathead mullet and some related fats and oils (Das, 1989; Williams, 1966, Helal et al., 2000, 2004).

\begin{tabular}{|c|c|c|c|c|c|c|c|c|c|c|c|c|}
\hline 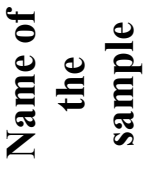 & $\dot{\vec{s}}$ & $\dot{\vec{s}}$ & 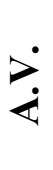 & 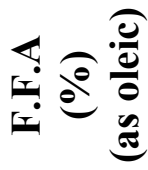 & $\dot{0}$ & $\dot{\square}$ & 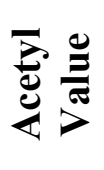 & 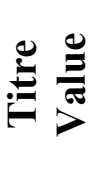 & $\sum_{\dot{p}}^{\dot{0}} e^{0}$ & $\sum_{\ddot{\prime}} \dot{>}$ & $\overrightarrow{\dot{a}}$ & $\dot{x}$ \\
\hline 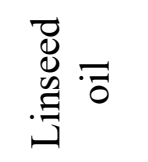 & $\frac{2}{a}$ & $\begin{array}{l}\text { ڤે } \\
\text { ते } \\
\frac{1}{\infty} \\
\text { N }\end{array}$ & $\stackrel{\odot}{\forall}$ & $\begin{array}{l}n \\
\vdots \\
0 \\
1 \\
0\end{array}$ & $\begin{array}{l}8 \\
\stackrel{8}{1} \\
\stackrel{1}{2} \\
=\end{array}$ & 1 & $\mid$ & $!$ & $\frac{n}{3}$ & $\mid$ & $!$ & $\begin{array}{l}\infty \\
\dot{\sigma}\end{array}$ \\
\hline 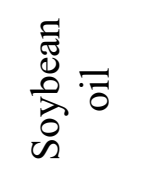 & $\frac{2}{2}$ & $\begin{array}{l}\stackrel{2}{2} \\
\frac{1}{\infty} \\
\text { d }\end{array}$ & 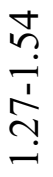 & $\begin{array}{l}n \\
\infty \\
0 \\
1 \\
n \\
n \\
0\end{array}$ & $\frac{\hat{n}}{\grave{n}}$ & $\begin{array}{l}n \\
\infty \\
1 \\
\\
\end{array}$ & $!$ & $\begin{array}{c}\text { तิ } \\
\text { ते }\end{array}$ & $\frac{0}{\frac{0}{1}}$ & 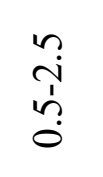 & مُ & $\mid$ \\
\hline 泀 & $\begin{array}{l}\stackrel{8}{ } \\
\text { } \\
\stackrel{n}{n} \\
n\end{array}$ & 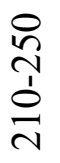 & $\begin{array}{l}\stackrel{0}{0} \\
\stackrel{1}{\prime} \\
\text { ñ } \\
\text { N }\end{array}$ & $\mid$ & $\begin{array}{l}0 \\
a \\
i \\
\infty\end{array}$ & $\frac{0}{1}$ & ! & ণ্ণ & $\begin{array}{l}r \\
0 \\
\stackrel{1}{0} \\
\ddot{0}\end{array}$ & $\begin{array}{l}0 \\
\infty \\
0 \\
0 \\
1\end{array}$ & 곤 & $\infty$ \\
\hline 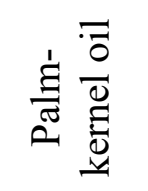 & $\stackrel{\infty}{\sim}$ & 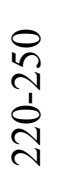 & $\mid$ & $\mid$ & $\frac{\infty}{n}$ & 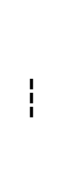 & ! & $!$ & $\mid$ & $\stackrel{\infty}{\sim}$ & ! & $\begin{array}{l}\text { J } \\
\text { ă }\end{array}$ \\
\hline 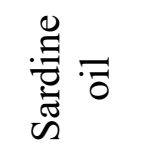 & 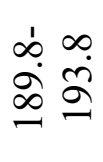 & ! & $\begin{array}{l}\text { I. } \\
\text { ்ָ } \\
\text { ்ָ }\end{array}$ & $\mid$ & $\begin{array}{l}\infty \\
\infty \\
\infty \\
\infty \\
\infty\end{array}$ & $!$ & $\mid$ & $\mid$ & $\mid$ & $\mid$ & $!$ & $!$ \\
\hline$\frac{\frac{0}{\pi}}{\sum_{3}^{3}}=\bar{\sigma}$ & $\begin{array}{l}\stackrel{8}{+} \\
\stackrel{+}{+} \\
\infty\end{array}$ & ! & 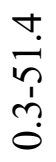 & $!$ & తి & $!$ & $\mid$ & $\mid$ & $\mid$ & $\mid$ & $!$ & $\mid$ \\
\hline 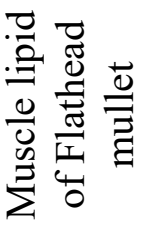 & $\stackrel{n}{\infty}$ & 仓े & $\begin{array}{l}\text { D) } \\
\text { i. }\end{array}$ & 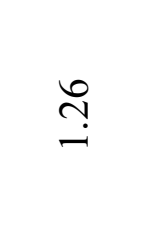 & 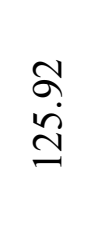 & $\begin{array}{l}\stackrel{8}{0} \\
\infty \\
0\end{array}$ & $\underset{\text { స̃ }}{=}$ & in & $\stackrel{0}{\rightleftarrows}$ & ๙̊ & ?ొ? & 2 \\
\hline
\end{tabular}

Abbreviations: S.V. $=$ Saponification value; S.E.V. $=$ Saponification equivalent value; A.V. $=$ Acid value; F.F.A. $=$ Free fatty acid; I.V. $=$ Iodine value; T.V. $=$ Thiocyanogen value; U.S.M. $=$ Unsaponifiable matter; R.M.V. = Reichert-Meissl value; P.V. = Polenske value; H.V. = Henher value. 


\section{1. Chemical characteristics}

The saponification value of the muscle lipid of Flathead mullet was found to be 182.5. The saponification equivalent of the muscle lipid of Flathead mullet was found to be 307.40 . Saponification value is inversely proportional to the average molecular weight or chain length of the fatty acids present in the fat or oil. The saponification equivalent is directly proportional to the average chain length of the fatty acids present in the fat or oil. The result clearly indicate that the lipid sample contain higher proportion of high molecular weight fatty acids.

The acid value of the muscle lipid of Flathead mullet was found to be 2.83 . The percentage of free fatty acid (EFA), as oleic, calculated from acid value was found to be 1.26. A low percentage of free fatty acid is an indication of suitability of the lipids for edible purpose. So the muscle lipid of Flathead mullet might be used for edible purpose.

The ester value of the muscle lipid of Flathead mullet was found to be 179.67. Iodine value gives an estimation of the degree of unsaturation and so, of the relative amounts of unsaturated fatty acids in the triglyceride molecules of the fat. The iodine value of the muscle lipid of Flathead mullet was found to be 125.92. The value indicates that the lipid sample contains moderate proportion of unsaturated fatty acids and is of semidrying type.

The peroxide value is an indication of unsaturation of fats or oils. The most unsaturated fats or oils absorb more oxygen, from greater amounts of unstable hydro peroxides and show higher peroxide value. The peroxide value of the muscle lipid of Flathead mullet was found to be 120.19 .

It can be concluded from the result the muscle lipid under investigation contained good amounts of unsaturated fatty acids. The thiocyanogen value of the muscle lipid of Flathead mullet was found to be 68.09. This observation is in conformity with the findings that the lipid sample has moderate iodine value and peroxide value. The acetyl value is a measure of hydroxylated fatty acids in a fixed oil or fat. The acetyl value of the muscle lipid of Flathead mullet was found to be 11.22. This result indicates low content of free hydroxyl groups in the lipid sample.

The titre value of the muscle lipid of Flathead mullet was found to be 27.6. This value indicates that the lipid sample is of fat type which supports the semisolid condition at room temperature. Unsaponifiable matter is defined as the substances which are not saponified by alkali and which are soluble in petroleum ether or ether. In general, if a fixed fat or oil has unsaponifiable matter present in excess of about $2 \%$, there is reason to support adulteration. The unsaponifiable matter in the muscle lipid of Flathead mullet was found to be $1.16 \%$. This result indicate that the lipid sample contain a small amount of unsaponifiable matter such as sterols, tocopherols, vitamins A \& D, hydrocarbons etc.

The Reichert-Meissl value of the muscle lipid of Flathead mullet was found to be 0.92 . Since the Reichert-Meissl value is a measure of the volatile water soluble lower fatty acids present in the fat or oil, so the low Reichert-Meissl value of the lipid sample is indication of low content of volatile water soluble fatty acids. The Polenske value of the muscle lipid of Flathead mullet was found to be 0.36 . The Polenske value represents a measure of volatile water insoluble but alcohol soluble fatty acids.

The low Polenske value as obtained is a support of the presence of small amount volatile water insoluble but alcohol soluble fatty acids in the lipid sample. The Henher value of the muscle lipid of Flathead mullet was found to be 79. This result higher percentage of water insoluble nonvolatile fatty acids present in the lipid sample.

The muscle lipid of Flathead mullet was found to form a treacle-like consistency with mercuric nitrate, $\mathrm{Hg}\left(\mathrm{NO}_{3}\right)_{2}$ solution after 24 hours during the experiment. Hence, the lipid is 
semi-drying type. The amount of cholesterol in the muscle lipid of Flathead mullet was found to be 33.25 .

\section{2. Estimation of $\mathrm{N}, \mathrm{P}, \mathrm{K}$ and $\mathrm{Ca}$ in muscle lipid of flathead mullet}

Table 2. Percent of nitrogen $(\mathrm{N})$, phosphorus $(\mathrm{p})$, potassium $(\mathrm{K})$ and calcium $(\mathrm{Ca})$ of the muscle lipid of Flathead mullet.

\begin{tabular}{lllll}
\hline $\begin{array}{l}\text { Name of the } \\
\text { sample }\end{array}$ & $\%$ of N $(\mathrm{g})$ & $\%$ of $\mathrm{P}(\mathrm{g})$ & $\%$ of K $(\mathrm{g})$ & $\%$ of Ca $(\mathrm{g})$ \\
$\begin{array}{l}\text { muscle lipid of } \\
\text { Flathead mullet }\end{array}$ & 9.95 & 0.4363 & 1.132 & 0.9
\end{tabular}

Most of the people of our country have been suffering to a great extent from protein malnutrition.

\section{3. Chromatographic examination}

The fatty acid methyl esters mixtures obtained from the muscle lipid of Flathead mullet was subjected to TLC examination and their fatty acid composition was identified by comparing the $\mathrm{R}_{\mathrm{f}}$ values of methyl esters of standard fatty acids in different solvent systems.

Table 3. The $\mathrm{R}_{\mathrm{f}}$ values (most related) of thin layer chromatographic examination of the muscle lipid of Flathead mullet (Mugil cephalus).

\begin{tabular}{|c|c|c|c|c|c|c|}
\hline \multirow[t]{3}{*}{ Solvent System } & \multicolumn{3}{|c|}{$R_{f}$ values of standard fatty acids } & \multirow{2}{*}{\multicolumn{3}{|c|}{$\begin{array}{c}\mathbf{R}_{\mathrm{f}} \text { values obtained from the spots } \\
\text { of Lipid sample }\end{array}$}} \\
\hline & \multirow[t]{2}{*}{ PA } & \multirow[t]{2}{*}{ SA } & \multirow[t]{2}{*}{ MA } & & & \\
\hline & & & & PA & SA & MA \\
\hline P:E (80:20) & 0.945 & 0.963 & 0.414 & 0.288 & 0.964 & 0.414 \\
\hline $\begin{array}{l}\text { P:E:A } \\
(80: 20: 1)\end{array}$ & 0.925 & 0.956 & 0.426 & 0.925 & 0.933 & 0.427 \\
\hline $\mathrm{H}: \mathrm{E}(80: 20)$ & 0.852 & 0.869 & 0.210 & 0.851 & 0.327 & 0.459 \\
\hline
\end{tabular}

Note; P: Petroleum ether, E: Ether, A: Acetic acid, H: Hexane

PA- Palmitic Acid, SA-Stearic Acid, MA- Myristic Acid.

\section{CONCLUSION}

Chemical characterization and antimicrobial studies of muscle of Flathead mullet (Mugil cephalus) were done in this investigation. Presence of good amount of sterols, tocopherols, vitamins A \& D, is considered with respect to U.S.M. Percentage of F.F.A validated suitability of the oil for edible purpose. Semi drying nature of the fish lipid was 
pointed out by I.V. Chromatographic examinations substantiated the presence of Palmitic acid, Stearic acid and Myristic acid in the muscle lipid. Protein and other important minerals $(\mathrm{Ca}, \mathrm{P}$ and $\mathrm{K})$ were also found with significant values in the muscle of Flathead mullet.

\section{ACKNOWLEDGEMENT}

I am highly indebted to Professor, Abdul Kader, the former Director, Institute of Marine Science and Fisheries, University of Chittagong for identifying the marine sample and his valuable advice and inspiration throughout my research work.

\section{References}

[1] Chowdhury M. N., Rashid H. U., Rahman H., Jahan S. S., Alam M. R., lqbal M., Bangladesh Renal Journal 2(1) (2001) 14-19.

[2] Das R. K. (1989). Industrial Chemistry, Part II, Kalyani Publishers, New Delhi, India, 250-259.

[3] Deckere De., EAM., European Journal of Cancer Prevention 8(3) (1999) 213-221.

[4] Griffin R. C. (1972). Technical Method of Analysis, 2nd Edn., McGraw-Hill Book Company, Inc., New York, 309, 319, 342.

[5] Helal Uddin M., Majid M. A., Chittagong Univ. J. Sci. 24(2) (2000) 83-89.

[6] Helal Uddin M., Majid M. A., Mistry A. C., Manchur M. A., Pak J. Sci. Ind. Res. 41(2) (2004) 121-I25.

[7] Loury M., Rev. Franc. Corps. Gras. 11 (1966) 259-272.

[8] Morris B. J. (1965). The Chemical Analysis of Foods and food Products, D. Van Nostrand Company. Inc., New York, 375, 382.

[9] Quazi S., Mohiduzzaman M., Rahman M., Ali S. M. K., Bangladesh Med. Res. Council Bull. 20(1) (1994) 1-7.

[10] Ranganna S. (1991). Handbook of Analysis and Quality Control for Fruit and vegetable Products, 2nd Edn., Tata McGraw-Hill Publishing Company Ltd., New Delhi, India, 3-226.

[11] Minckley W. L. (1973). Fishes of Arizona. Arizona Game and Fish Department, Phoenix. 257-258.

[12] Rajagopalan V., Abinaya G., Balasubramanian U., Journal of Science \& Innovative Research 2(2) (2013) 303-319.

[13] Siddique L. N., Ali M. S., Jahan S. S., Muslemuddin M., Begum S. N., Bangladesh J. Pathology 9(2) (1994) 10-13.

[14] Siddique L. N., Ali M. S., Begum S. N., Muslemuddin, M., Jahan S. S., Bangladesh J. Physiol. Pharmacol. 11(1) (1995a) 22-27. 
[15] Siddique L .N., Ali M. S., Begum S. N., Jahan S. S., Muslemuddin M., J. Dhaka Medical Callege 4(1) (1995b) 13-17.

[16] Sankar S., Sujith P., Jayalakshmi S., International Journal of Pharmacy and Biological Sciences 3(3) (2013) 398-404.

[17] Williams K. A. (1966). Oils, Fats and Fatty Foods, $4^{\text {th }}$ Edn., J. \& A. Churchill Ltd. 